\title{
Famílias e Violência Doméstica: Condições Psicossociais Pós Ações do Conselho Tutelar
}

Families and domestic violence: Psychosocial characterization post actions from the Child Protection Agency

Rute Grossi Milani \&

Sonia Regina Loureiro

Faculdade de Medicina de Ribeirão Preto

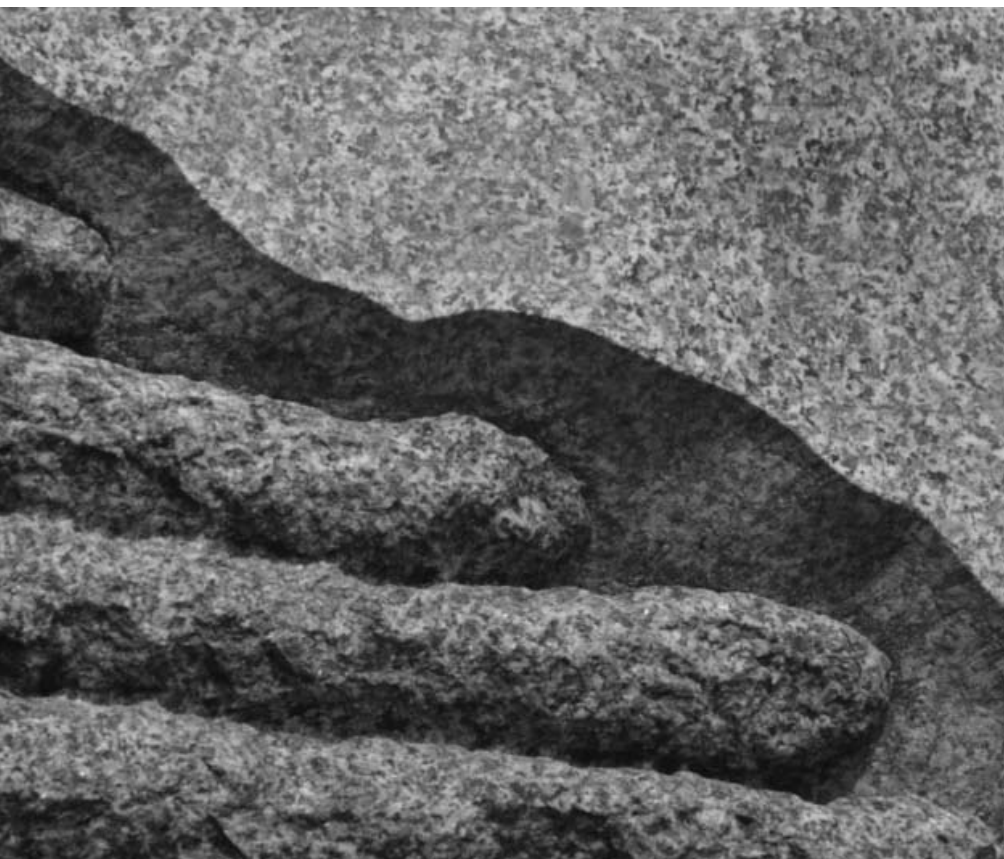


Resumo: O texto aborda as condições familiares implicadas em situações de risco psicossocial, focalizando o problema da violência doméstica e suas repercussões no desenvolvimento psicossocial de crianças. A discussão abarca funções e medidas de proteção aplicadas pelo Conselho Tutelar, partindo da avaliação de famílias notificadas por violência doméstica há três anos. A pesquisa compara recursos e adversidades dessas famílias, considerando um grupo de famílias sem história de risco psicossocial. Foram investigadas quarenta famílias, com filhos em idade escolar, que compuseram dois grupos, cada um com vinte crianças, sendo um com histórico de violência doméstica e outro sem risco relatado. Os instrumentos da investigação foram: entrevista semi-estruturada, inventário de recursos do ambiente familiar e escala de eventos adversos. Os tipos de violência observados predominantemente foram: negligência dos responsáveis, seguida de violência física e psicológica. São destacadas as diferenças quanto à ocorrência de adversidade parental e semelhanças quanto aos recursos do ambiente familiar.

Palavras-chave: Violência na família. Ambiente familiar. Conselho Tutelar. Intervenção psicossocial.

\begin{abstract}
The text addresses the family conditions implied in situations of psychosocial risk, focused on domestic violence and its effects on the children's psychosocial development. The discussion covers the functions and the protection measures used by the Child Protection Agency, based on the evaluations of families that have been notified due to domestic violence three years ago. The research compares the families' resources and adversities to a group of families with no previous psychosocial risk. Forty families with school-aged children were surveyed. Two groups were arranged (20 children each): families with cases of domestic violence and families with no reported risk. The investigation tecniques included: semi-structured interviews with the familiar environment resources inventory and the adverse events scale. The prevailing types of violence observed were the negligence by parents/guardians followed by physical and psychological violence. Emphasis is given to the differences regarding the occurrence of parent adversity and similarities in the family environment resources.
\end{abstract}

Keywords: Family violence. Family environment. Child Protection Agency. Psychosocial intervention.

O ambiente familiar constitui uma área de interesse crescente em pesquisas sobre o desenvolvimento infantil. Tal interesse traz como implicação a análise dos recursos e adversidades desse ambiente e a avaliação de padrões de interação entre pais e filhos. Com base nas proposições de Marturano (1999) e de Reppold, Pacheco, Bardagi e Hutz (2002), pretende-se compreender as condições pessoais das crianças e do ambiente familiar, considerando como operam para favorecer ou dificultar o desenvolvimento infantil.

As transformações familiares e socioculturais da sociedade atual podem atuar no sentido de favorecer condições de risco psicossocial. Neste trabalho, a expressão risco psicossocial significa a presença de eventos negativos e circunstâncias sociais que afetam o bemestar da criança e da família e que limitam a capacidade adaptativa frente a eventos futuros, o que, segundo Yunes e Symanski (2001), pode aumentar a probabilidade de ocorrência de problemas físicos, emocionais ou comportamentais no indivíduo.

A infância não é um período protegido da influência de eventos negativos, pelo contrário, pode ser permeada por situações adversas inerentes ao contexto proximal familiar 
A violência no contexto familiar constitui um fenômeno complexo que envolve questões como a desigualdade social e prejuízos na qualidade de vida que atingem as famílias com comprometimento nas relações intrafamiliares, e é evidenciado pelo abuso de poder. ou ao contexto social mais amplo. Nesse sentido, as dificuldades comportamentais, muitas vezes, emergem associadas a esses contextos de vida, o que sugere a necessidade de estudos sistemáticos desenvolvidos junto a crianças expostas a riscos psicossociais que poderão instrumentar programas de intervenção relativos a tal população (Rutter, 1996). Dentre as condições mais adversas do contexto proximal às quais as crianças podem estar expostas, inclui-se a violência familiar.

A violência no contexto familiar constitui um fenômeno complexo que envolve questões como a desigualdade social e prejuízos na qualidade de vida que atingem as famílias com comprometimento nas relações intrafamiliares, e é evidenciado pelo abuso de poder. De acordo com o Estatuto da Criança e do Adolescente - ECA (Brasil, 1990), a violência doméstica direcionada à criança pode ser caracterizada como violência física, psicológica, sexual e negligência. A caracterização dos diferentes tipos de violência não é simples, por tratar-se de fenômeno heterogêneo que envolve a vida privada, sendo por vezes difícil circunscrevê-lo.

Segundo Deslandes (1994), os tipos de violência podem ser assim definidos: a) violência física - ação única ou repetida, intencional, cometida por um adulto ou pessoa mais velha que a criança ou adolescente, que provoque dano físico, de grau variado de lesão que leve até à morte; b) violência psicológica - envolve um padrão de comportamento destrutivo do adulto, que interfere negativamente na competência social da criança, por meio de práticas de rejeição, isolamento, ameaça, descaso, corrupção, expectativas e exigências irreais, e c) violência sexual - ato ou jogo sexual, com a intenção de estimular sexualmente ou de usar a criança ou adolescente para obter satisfação sexual por parte de adulto ou de pessoa em estágio mais avançado de desenvolvimento. A negligência, segundo Guerra (1998) e Riva (2006), pode ser caracterizada como o abandono parcial ou total dos responsáveis e/ou a omissão na provisão das necessidades básicas e da supervisão essencial à segurança e ao desenvolvimento da criança, quando não associadas a privações socioeconômicas.

Estudos sobre a violência direcionada à criança, com amostras referidas para serviços de proteção, evidenciam que tais crianças apresentam maior risco de apresentar problemas de comportamento, de ajustamento acadêmico e de percepção social negativa (Lisboa et al., 2002, Shonk \& Cicchetti, 2001; Toth, Cicchetti, \& Kim, 2002).

A violência doméstica pode estar associada a variáveis do ambiente familiar, como psicopatologia dos pais, discórdia conjugal, baixa renda familiar e outros eventos de vida, como a experiência de separação e perda ( Cummings, Pepler, \& Moore, 1999; Grych, Jouriles, Swank, Mcdonald, \& Norwood, 2000; Jouriles et al., 1998).

Cummings et al. (1999) estudaram os efeitos da violência interparental no comportamento da criança e observaram que variáveis maternas, tais como o nível educacional e intelectual, atuaram como moderadores da violência. English, Marshall e Stewart (2003), ao avaliarem o comportamento e as condições de saúde de crianças vítimas de violência e suas associações com características dos responsáveis, constataram que os problemas de saúde geral dos responsáveis e de interação social com as crianças se relacionaram com a violência interparental e com os problemas de comportamento na criança. 
De um modo geral, os estudos sobre a violência doméstica chamam a atenção para a necessidade de explorar os fatores do ambiente familiar que se associam a essa condição de risco. Tais estudos também sinalizam a necessidade de suporte tanto para as crianças como para as famílias que experimentam tal adversidade.

Nesse sentido, a presença de uma rede de apoio social pode favorecer a ativação de recursos pessoais das crianças e da família para o enfrentamento dos estressores e das adversidades. A rede de apoio envolve todos os recursos disponíveis do indivíduo e do seu meio social. Incluem-se como tal a família, a escola e as instituições com as quais a criança tem contato, explicitando-se a sua ação no suporte direto de pessoas e no suporte institucional mediado por políticas e programas públicos.

Em nosso meio, o Conselho Tutelar caracterizase como um órgão da rede de apoio institucional às crianças e famílias em risco psicossocial. Considera-se que as decisões tomadas, as interações estabelecidas e as expectativas geradas pelo Conselho Tutelar podem influenciar a resposta à situação de risco psicossocial e o desenvolvimento infantil.

Os Conselhos Tutelares surgiram por lei federal (ECA-Brasil, 1990). Constituem órgãos estruturados nos Municípios para garantir a defesa dos direitos fundamentais das crianças e adolescentes sempre que esses são violados. Frente à ocorrência de violação de direitos da criança e do adolescente, o trabalho dos Conselhos Tutelares torna a intervenção mais imediata, com a aplicação de medidas de proteção e providências administrativas, que permitem o ressarcimento de seus direitos.
Quando a denúncia apresentada se refere a uma situação de violência doméstica, o Conselho tem poderes para aplicar uma série de medidas que buscam garantir a proteção da criança. As medidas podem envolver desde a orientação, $\mathrm{O}$ apoio e acompanhamento temporário à família, realizadas pelo próprio conselheiro, até ações de suspensão do pátrio poder.

A aplicação dessas medidas visa a prevenir a reincidência da violência no ambiente familiar. Ressalta-se, porém, que o Conselho Tutelar possui atuação de caráter administrativo e não-assistencial, e tem a função de executar atribuições constitucionais e legais no campo da proteção à infância e juventude. Cabe ainda aos conselheiros reivindicar políticas públicas de proteção infanto-juvenil, porém a criação de novas políticas públicas ou as alterações de políticas existentes é de responsabilidade do Conselho Municipal de Direitos da Infância e da Adolescência (Santos, 1999).

A descrição do trabalho desenvolvido pelo Conselho Tutelar evidencia o seu papel de disparador das redes de serviços de apoio, buscando desenvolver competências, por meio da valorização das potencialidades humanas, com a finalidade de melhorar a saúde das comunidades.

Analisando-se a literatura nacional recente relativa a estudos sobre o Conselho Tutelar, destacam-se quatro relatos, dois que enfocam as relações estabelecidas com a escola, e dois, as concepções e práticas vigentes nesse órgão.

Parré (2005) pesquisou como a relação escola - Conselho Tutelar assegura o exercício dos direitos e deveres da criança, partindo do 
pressuposto que as instituições que se ocupam das crianças e dos adolescentes se articulam e adotam processos de normatização e controle. A autora assinala que, para garantir uma definição mais clara de seu papel e função, o Conselho Tutelar tem o desafio de desenvolver ações preventivas e educativas apesar de ele mesmo não ser um programa de atendimento ou uma entidade de assistência. Conclui que são as ações em rede, que envolvem todo o sistema social (família, escola, Estado), que garantem a efetivação dos direitos das crianças e dos adolescentes.

Souza, Teixeira e Silva (2003) buscaram compreender a aplicação das prerrogativas estabelecidas pelo ECA acerca do direito à escolarização. Para isso, acompanharam o trabalho de um Conselho Tutelar e verificaram que a maioria dos encaminhamentos poderia ser tratada na própria escola, e constataram a ausência de ações conjuntas voltadas para o enfrentamento das causas educacionais que denunciam o desrespeito a direitos fundamentais.

Castro (2002) conduziu um estudo sobre o ECA, relacionando-o com as ações do Conselho Tutelar enquanto lugar de operacionalização do mesmo. O estudo foi conduzido segundo o referencial metodológico da fenomenologia, e o ECA foi apresentado como responsável pela produção de um novo saber, que é significativo para a vida das crianças, mas que pode ter seu sentido original burocratizado no cotidiano das ações do Conselho Tutelar. Argumenta que existe a possibilidade de retorno ao sentido original do ECA, em seu espaço de ação via Conselho Tutelar, na medida em que se volta ao fundamento ético, que se aproxima da condição humana e da compreensão dos direitos de crianças e adolescentes.
Com o objetivo de identificar as concepções e práticas dos Conselhos Tutelares acerca da violência doméstica, Peres (2001) desenvolveu um estudo em seis Conselhos Tutelares do Município de Curitiba. O estudo mostrou que as práticas acerca da violência contra a criança se caracterizam como assistencialistas, e que o conselheiro apresenta um sentimento de impotência em relação a seu trabalho frente ao contexto sociopolítico.

Destaca que a vivência de conselheiro tutelar e a ação frente à realidade de violência estrutural vivida pela população têm contribuído para a mudança na concepção de violência, predominando, entre os conselheiros, a noção de violência dos direitos.

Considerando-se que o Conselho Tutelar, enquanto suporte institucional, é um órgão relativamente recente no combate aos riscos psicossociais em nossa sociedade, torna-se relevante avaliar como famílias que foram atendidas por esse órgão e receberam medidas de proteção por estarem expostas à violência doméstica se encontram um tempo depois de tal suporte. Tal interesse motivou a primeira autora deste estudo a buscar sistematizar a sua prática, enquanto foi psicóloga junto ao Conselho Tutelar de Maringá. Tal Conselho foi o primeiro a entrar em funcionamento no Brasil, em 1991, e contou, por dez anos, com uma equipe técnica multidisciplinar, composta por psicólogo, pedagogo, assistente social e advogado.

Nesse sentido, objetivou-se: a) caracterizar as condições de risco psicossocial e as medidas de proteção aplicadas pelo Conselho Tutelar há três anos a famílias notificadas por violência doméstica; b) comparar os recursos 
e adversidades de um grupo de famílias atendidas há três anos pelo Conselho Tutelar por violência doméstica com um grupo de famílias sem história de risco psicossocial relatada quanto à violência doméstica.

Ao se destacar o papel de provisão de suporte à criança e famílias por parte do Conselho Tutelar, enquanto órgão de proteção a um risco amplamente reconhecido e complexo como a violência doméstica, considera-se que os dados coletados junto às famílias poderão instrumentar novos estudos sobre práticas remediativas e psicoprofiláticas em relação à população envolvida.

\section{Método}

\section{Participantes}

Foram avaliadas quarenta famílias, com filhos na faixa etária de 8 a 12 anos incompletos, de ambos os sexos, distribuídas em dois grupos: vinte incluídas no grupo 1 (G1) = risco psicossocial -violência doméstica, atendidas junto ao Conselho Tutelar do Município de Maringá - Paraná, há três anos, após uma primeira denúncia de risco psicossocial associado a violência doméstica, e vinte incluídas no grupo $2(\mathrm{G} 2)=$ sem história de risco psicossocial relatada. Entende-se como risco psicossocial o relato de um conjunto de fatores relacionados à violência física, violência psicológica direcionadas à criança, negligência e a violência entre os pais presenciada pela criança.

Para a seleção dos quarenta participantes, foram contatadas cento e seis famílias, cinqüenta e oito como possíveis integrantes do G1, e quarenta e oito, como possíveis integrantes do G2. Para G1 e G2, foram excluídas do estudo crianças institucionalizadas, com história de adoção, que sofreram violência sexual, com deficiência física ou mental evidente, e, como condição de inclusão geral para G1 e G2, a residência com pelo menos um dos pais biológicos.

As crianças do G1 foram identificadas nos registros do banco de dados do Conselho Tutelar de Maringá mediante autorização do Juiz da Vara da Infância e Juventude de Maringá. O G2 foi formado por crianças sem história prévia ou atual de qualquer situação familiar que tenha requerido a intervenção do Conselho Tutelar. Procurouse, na constituição desse grupo, tendo por referência as características do G1, pareá-lo quanto ao sexo e balanceá-lo quanto à idade atual, à série escolar, ao nível cognitivo, à residência com pelo menos um dos pais biológico, à ausência de deficiência física ou mental evidente e a características socioeconômicas familiares semelhantes. Identificaram-se essas crianças nas escolas freqüentadas pelas incluídas no G1.

A caracterização dos dois grupos que serão nomeados como G1 = risco psicossocial violência doméstica, e G2= sem história de risco psicossocial relatada, quanto às variáveis gênero, idade, nível intelectual, escolaridade das crianças e dos pais e nível socioeconômico da família será apresentada na Tabela 1. 
Tabela 1 - Características sociodemográficas das crianças e famílias dos dois grupos, expressas em freqüência

\begin{tabular}{|c|c|c|c|}
\hline & Variável & $\begin{array}{l}\text { Grupo } 1 \\
(n=20)\end{array}$ & $\begin{array}{l}\text { Grupo } 2 \\
(n=20)\end{array}$ \\
\hline \multirow[t]{2}{*}{ Gênero } & Masculino & 12 & 12 \\
\hline & Feminino & 08 & 08 \\
\hline \multirow[t]{2}{*}{ Idade } & 8 e 9 anos & 05 & 07 \\
\hline & 10 e 11 anos & 15 & 13 \\
\hline Nível Intelectual & $=\mathrm{III}+$ & 11 & 14 \\
\hline (Raven) Médio & $=\mathrm{III}-$ & 09 & 06 \\
\hline Escolaridade - criança & $1 \underline{\underline{a}}$ e $2^{\underline{a}}$ & 02 & 01 \\
\hline \multirow{2}{*}{ (série em curso) } & $3^{\underline{a}}$ e $4 \underline{a}$ & 13 & 13 \\
\hline & $5^{\underline{a}}$ e $6^{\underline{a}}$ & 05 & 06 \\
\hline \multirow{6}{*}{$\begin{array}{l}\text { Escolaridade - pai } \\
\text { (em anos) }\end{array}$} & Não Informado & 01 & 00 \\
\hline & $1-2$ anos & 01 & 01 \\
\hline & $3-4$ anos & 02 & 07 \\
\hline & $5-6$ anos & 07 & 03 \\
\hline & $7-8$ anos & 04 & 04 \\
\hline & Mais de oito anos & 05 & 05 \\
\hline \multirow{6}{*}{$\begin{array}{l}\text { Escolaridade - mãe } \\
\text { (em anos) }\end{array}$} & Analfabeto & 01 & 01 \\
\hline & $1-2$ anos & 01 & 01 \\
\hline & $3-4$ anos & 03 & 03 \\
\hline & $5-6$ anos & 05 & 03 \\
\hline & $7-8$ anos & 05 & 05 \\
\hline & Mais de oito anos & 05 & 07 \\
\hline \multirow[t]{3}{*}{ Nível socioeconômico } & $A-B$ & 03 & 05 \\
\hline & $\mathrm{C}$ & 09 & 08 \\
\hline & $D-E$ & 08 & 07 \\
\hline
\end{tabular}

G1 = risco psicossocial - violência doméstica $\quad=I I I+$ : Médio ao Superior

$\mathrm{G} 2=$ sem história de risco psicossocial relatada =III-: Médio ao Médio Inferior

Os critérios de composição dos grupos foram analisados de forma sistemática, por meio de tratamento estatístico dos dados relativos à idade e ao nível intelectual da criança, à escolaridade da criança e dos pais e ao nível socioeconômico da família. Não foram observadas diferenças estatisticamente significativas em relação a tais variáveis analisadas.

A Tabela 2 apresenta a composição familiar do G1 e do G2.

Tabela 2- Características dos grupos em relação à composição familiar das crianças estudadas, expressas em freqüência

\begin{tabular}{lll}
\hline Composição familiar & Grupo 1 & Grupo 2 \\
\hline Mãe, pai e irmãos & 4 & 15 \\
Mãe, irmãos & 8 & 2 \\
Só a mãe & 1 & 1 \\
Mãe (ou pai), padrasto (ou madrasta), irmãos & 7 & 2
\end{tabular}

G1 = risco psicossocial - violência doméstica

$\mathrm{G} 2=$ sem história de risco psicossocial relatada 
Três famílias do G1 e três do G2 informaram a presença de outros familiares no mesmo domicílio, além da família de origem, incluindo tio, sobrinho, cunhado e primo. Em três famílias do G1, o pai havia falecido, fato que ocorreu após a separação dos pais.

No G1, em treze famílias, o estado civil do responsável era separado, e, em sete, casado. Em seis famílias do G1, os pais permaneciam casados; em duas, os pais estavam ausentes, um, por ter sido preso, e o outro, por estar trabalhando no exterior. No G2, em dezoito famílias, o responsável estava casado, e, em duas, separado.

Instrumentos e materiais

Entrevista semi-estruturada para os pais realizada individualmente (para investigar), com base em um roteiro de doze itens, que abordava, além de três tópicos relativos à história prévia de atendimento pelo Conselho Tutelar (1. Já precisou buscar ajuda junto ao Conselho Tutelar? Como foi? Quantas vezes e em que época? Motivos? Como se sentiu? 2. O que foi feito pelo Conselho Tutelar? Foram aplicadas medidas? Foram seguidas? 3. Já recebeu a visita do SOS Criança em sua casa? Motivos?), a dependência química, a constituição familiar, as rotinas adotadas e outras dificuldades enfrentadas pela família. Teve por objetivo principal a avaliação da história de maus- tratos para o G1 e a exclusão de tal condição para o G2. O tempo médio de aplicação foi de 50 minutos.

Inventário de recursos no ambiente familiar (RAF) - roteiro de entrevista semi-estruturada elaborado por Marturano (1999), visa à sondagem dos recursos do ambiente familiar, e tem o objetivo de obter dados sobre condições relevantes para o desempenho escolar. É aplicado sob a forma de entrevista semi-estruturada, na qual cada tópico é iniciado por pergunta aberta seguida de questões fechadas, podendo-se esclarecer dúvidas, caso se faça necessário. Compõese de três módulos, subdivididos em treze tópicos, com um número variável de itens, a saber: A) supervisão e organização das rotinas (cinco tópicos), B) oportunidades de interação com os pais (quatro tópicos), C) presença de recursos no ambiente físico (quatro tópicos).

Escala de eventos adversos (EEA) - elaborada por Marturano (1999). Essa escala contém eventos adversos que podem ter ocorrido nos últimos doze meses, ou anteriormente, na vida da criança. É formada por trinta e cinco itens. A escala é preenchida a partir de informações colhidas com os pais, através da leitura de uma lista de situações que podem ocorrer na vida das crianças.

Escala de adversidade crônica (EAC) consiste em uma lista de quatorze condições adversas crônicas, definidas como adversidade prolongada (com duração de mais de doze meses) ou recorrente (ocorrência repetida durante um ano ou mais), também elaborada por Marturano (1999), a partir de informações dadas espontaneamente pelas mães em entrevistas.

Critério de classificação socioeconômica Brasil (CCSEB) - (Associação Brasileira de Anunciantes - ABA; Associação Nacional das Empresas de Pesquisa de Mercado - ANEP; Associação Brasileira dos Institutos de Pesquisa de Mercado - ABIPEME, 1997) - empregado para a avaliação da classe e o balanceamento dos grupos.

Fichas de registro do Conselho Tutelar informações relativas aos tipos de violações relatadas, estressores associados e medidas de proteção aplicadas à família.

Procedimento de coleta dos dados

Visando ao cumprimento das normas éticas relacionadas à pesquisa científica, o estudo em questão foi apreciado e aprovado pelo Comitê de Ética da Universidade Estadual de Maringá (Processo no 068/02 - COPEP). Precedendo a coleta de dados, a pesquisadora apresentou os 
objetivos do estudo às famílias e esclareceu o tipo de participação requerida, destacando o compromisso de sigilo em relação aos dados individuais obtidos na pesquisa e a garantia de liberdade aos participantes para desistirem do estudo a qualquer momento, sem que isso acarretasse prejuízo a eles. Ressaltou-se a disponibilidade para a devolutiva individual dos dados para os pais e crianças, com base na manifestação de interesse, o que foi feito sob a forma de orientações individuais. Após a assinatura do termo de consentimento livre e esclarecido por parte dos pais e a aceitação da participação por parte da criança, teve início a coleta de dados.

As atividades de coleta de dados para os dois grupos foram simultâneas, realizadas na Clínica de Psicologia do Centro Universitário de Maringá, e distribuídas da seguinte forma:

1a sessão: Os pais responderam a uma entrevista semi-estruturada, face a face, a respeito de aspectos gerais dos cuidados com seu filho e aspectos específicos relativos à violência doméstica, com ou sem história prévia de acompanhamento pelo Conselho Tutelar, e história de dependência química atual ou pregressa por parte dos pais. A entrevista foi gravada em áudio mediante consentimento específico para tal. Com relação ao $\mathrm{G} 2$, quando havia relato de violência doméstica ou história psiquiátrica dos pais, concluía-se a avaliação com a família, mas esta não era incluída no estudo. A segunda sessão só foi realizada com os familiares do G1 e do G2 que atenderam aos critérios de inclusão já explicitados.

$2^{\text {a }}$ sessão: Os pais responderam ao inventário de recursos no ambiente familiar (RAF), à escala de eventos adversos (EEA), à escala de adversidade crônica (EAC) e ao critério de classificação socioeconômica. Todas as aplicações foram realizadas face a face, as questões foram lidas e a pesquisadora assinalava as respostas fornecidas.

O tempo médio de coleta de dados foi de aproximadamente uma hora e meia com cada família.

Procedimento de análise dos dados

As entrevistas foram categorizadas e quantificadas sob a forma de freqüência. Os subtipos de maus-tratos foram assim classificados : a) violência física - ações não acidentais cometidas por pais e responsáveis que resultaram em dano físico, decorrente de punição física; b) violência psicológica - atos de rejeição, depreciação e agressões verbais dos pais direcionados às crianças; c) negligência - abandono por parte dos pais, descuido em relação à alimentação, segurança e educação da criança e d)violência interparental presenciada pela criança, quando da exposição da criança à violência praticada pelo pai ou padrasto em relação à mãe, caracterizando violência contra a mulher.

Os dados relativos ao inventário e escalas foram codificados de acordo com as recomendações das técnicas, e os grupos foram comparados por meio de testes estatísticos para amostras independentes, com a adoção do nível de significância de $p \geq 0,05$.

\section{Resultados}

Condições de risco psicossocial e medidas de proteção

Para a caracterização dos riscos psicossociais, destacou-se o tipo de violência relatado nos registros do Conselho Tutelar para as famílias do G1, atendidas há três anos. Consideraramse todas as ocorrências relativas à violência doméstica, e aproximadamente na metade das famílias, os filhos sofreram mais de um tipo de violência. Com relação à violência direcionada à criança $(n=17)$, predominou 
Os pais foram os violadores mais freqüentes. Em função da diversidade e do tamanho da amostra, não se considerará a análise específica dos subtipos de violência no lar. a negligência $(n=09)$, seguida pela violência física $(n=07), e$, por último, pela violência psicológica $(n=06)$. Destaca-se que, em três famílias da amostra, os filhos não sofreram violência física, mas foram expostos à violência interparental. A violência interparental presenciada pela criança esteve presente em dez casos, apresentando-se sob a forma de violência física e psicológica. Os pais foram os violadores mais freqüentes. Em função da diversidade e do tamanho da amostra, não se considerará a análise específica dos subtipos de violência no lar.

Com base nas informações obtidas nos registros do Conselho Tutelar, verificouse, ainda, que, em três famílias, os filhos tinham experienciado exclusivamente risco psicossocial associado à violência interparental, caracterizada por violência contra a mulher. Dezessete famílias tinham experienciado outros estressores no momento da denúncia, como discórdia parental recorrente $(n=15)$ e uso ou abuso de álcool e drogas pelos pais $(n=12)$. Em onze casos, essas duas condições se mostraram associadas. Foram também identificados, com menor freqüência, os seguintes estressores: desemprego $(n=5)$, situação de pobreza extrema $(n=2)$ e envolvimento com a lei devido a tráfico de drogas por parte dos pais $(n=1)$.

Quanto às medidas de proteção aplicadas pelo Conselho Tutelar, em todos os casos, os norteadores foram as medidas de orientação legal, baseadas ECA, e, dependendo do caso, as medidas priorizaram as áreas social, de saúde mental ou jurídica.

Com relação à área social, foram realizados sete encaminhamentos para programas de proteção social, quatro para programas socioeducacionais, com atendimento em período integral à criança, e três para abrigo temporário, no qual permaneceram por poucos dias. Os encaminhamentos para abrigo ocorreram pelos seguintes motivos: não localização dos pais, falta de condições dos pais para receber a criança de volta ao lar devido ao risco de nova situação de violência e violência interparental, ou seja, violência contra a mulher, na qual a criança ficou acompanhada pela mãe e irmãos no abrigo.

Ao todo, foram realizados quatorze encaminhamentos para a área de saúde mental. Destes, seis foram voltados para as crianças, sendo cinco encaminhadas para atendimento psicológico, por apresentarem dificuldades comportamentais e ou emocionais que precediam o evento que motivou a denúncia, e uma foi também encaminhada para atendimento psiquiátrico por apresentar sintomas psicóticos. Os oito encaminhamentos direcionados aos pais envolveram o atendimento psicológico, principalmente para tratamento do alcoolismo. Os encaminhamentos jurídicos foram feitos a oito famílias, e envolveram medidas de assistência ligadas à indefinição de guarda, ou seja, não definição da responsabilidade sobre o cuidado da criança e ao não recebimento de pensão alimentícia. Também ocorreu a aplicação de sanções aos pais em dois casos, quando da presença de hematomas e escoriações nos filhos, fato que exigiu o registro da denúncia de violência física junto à delegacia.

Em todos os casos, após a aplicação das medidas, os pais foram solicitados a assinar o termo de responsabilidade, comprometendo-se a seguir as orientações e os encaminhamentos dados.

Variáveis relativas ao ambiente familiar

Recursos do ambiente familiar

Os dados relativos à comparação dos grupos quanto ao escore total e os módulos relativos aos recursos do ambiente familiar são apresentados na Tabela 3. 
Tabela 3 - Recursos do Ambiente Familiar: Média, Desvio Padrão e Mediana relativos ao Escore Total, aos módulos e às comparações dos grupos G1 e G2

\begin{tabular}{lcccccc}
\hline Recursos do ambiente & \multicolumn{2}{c}{ G1 } & \multicolumn{2}{c}{ G2 } & p* & Comparações \\
Módulos & Média (DP) & Mediana & Média (DP) & Mediana & & \\
\hline Total & $86,01(11,54)$ & 84,86 & $86,74(10,46)$ & 87,46 & 0,83 & NS \\
$\begin{array}{l}\text { A) Supervisão e Org. } \\
\text { das Rotinas }\end{array}$ & $42,93(7,92)$ & 43,66 & $42,72(7,47)$ & 43,91 & 0,93 & NS \\
B) Interação com os Pais & $23,64(3,74)$ & 23,86 & $25,35(3,51)$ & 24,91 & 0,14 & NS \\
C) Presença de Recursos & $19,45(3,76)$ & 20,64 & $18,67(3,28)$ & 17,89 & 0,49 & NS \\
\hline
\end{tabular}

Teste t de student $\quad \mathrm{NS}=$ não significativo $\quad * \mathrm{p}=0,05$

$\mathrm{G} 1=$ risco psicossocial - violência doméstica $\mathrm{G} 2$ = sem história de risco psicossocial relatada

Não se observaram diferenças estatisticamente significativas entre os grupos, tanto em relação ao escore total como em relação aos três módulos, a saber: organização das rotinas, interação com os pais e presença de recursos no ambiente físico e respectivos tópicos.

Os grupos também foram comparados quanto a cada um dos itens da escala. Observaramse diferenças com relação aos módulos, a saber: A) supervisão e organização das rotinas, em que os filhos das famílias do G1 apresentaram maior proporção no item 5, "fica na rua", do Tópico 1 - o que a criança faz quando não está na escola, sugerindo que mais crianças do G1, comparativamente ao G2, ficam na rua, sem supervisão direta no período em que não estão na escola, e B) oportunidades de interação com os pais, os filhos das famílias do G1 apresentaram uma proporção menor quando comparadas com os filhos das famílias do G2 nos itens onze e dezoito, relativos a "ir ao museu" e à "exposição", do tópico 3 - passeios proporcionados/compartilhados com os pais, e no item "brincar", do tópico 5 - atividades que os pais desenvolvem junto com o filho em casa. Tais diferenças sugerem menos oportunidades de interação com os pais, tendo em conta os itens específicos avaliados.

Eventos adversos - atuais, pregressos e crônicos

Os dados relativos à comparação dos grupos quanto aos eventos adversos relatados após três anos do atendimento de G1 pelo Conselho Tutelar são apresentados para o escore total e para as dimensões temporais, como mostra a Tabela 4.

Foram observadas diferenças estatisticamente significativas com relação ao escore total e quanto às dimensões temporais, indicando a presença de mais adversidades para as famílias do G1 na comparação com as famílias do G2. Tais adversidades envolveram principalmente as relações interpessoais, as perdas e a instabilidade financeira.

Os grupos foram comparados em relação às áreas específicas da escala de eventos adversos, enfocando-se os eventos atuais e pregressos relatados após três anos do atendimento do G1 pelo Conselho Tutelar, como mostra a Tabela 4. 
Tabela 4 - Eventos Adversos Atuais e Pregressos: Média, Desvio Padrão e Mediana relativos às áreas, às categorias e às comparações dos grupos G1 e G2

\begin{tabular}{|c|c|c|c|c|c|c|c|}
\hline \multirow{2}{*}{\multicolumn{2}{|c|}{ Areas/ Categorias }} & \multicolumn{2}{|c|}{ G1 } & \multicolumn{2}{|c|}{$\mathrm{G} 2$} & \multirow[t]{2}{*}{$\mathrm{p}^{*}$} & \multirow{2}{*}{$\begin{array}{l}\text { Compa- } \\
\text { rações }\end{array}$} \\
\hline & & Média (DP) & Mediana & Média (DP) & Mediana & & \\
\hline \multicolumn{8}{|l|}{ B) Adversidade } \\
\hline \multicolumn{8}{|c|}{ Parental } \\
\hline \multirow[t]{2}{*}{ Escore Total } & Atual• & $2,90(1,61)$ & 3 & $1,45(1,31)$ & 1 & 0,01 & $\mathrm{G} 1>\mathrm{G} 2 *$ \\
\hline & Pregressa & $8,00(2,48)$ & 8,5 & $3,30(2,15)$ & 2,5 & 0,01 & $\mathrm{G} 1>\mathrm{G} 2 *$ \\
\hline \multicolumn{8}{|l|}{ 1) Relações } \\
\hline \multirow[t]{2}{*}{ Parentais } & Atual• & $0,80(0,89)$ & 1 & $0,30(0,57)$ & 0 & 0,04 & $\mathrm{G} 1>\mathrm{G} 2 *$ \\
\hline & Pregressa • & $3,10(1,70)$ & 3,5 & $0,55(1,05)$ & 0 & 0,01 & $\mathrm{G} 1>\mathrm{G} 2 *$ \\
\hline \multicolumn{8}{|c|}{ 2) Condutas } \\
\hline Parentais & Atual• & $0,50(0,51)$ & 0,5 & $\begin{array}{c}5,000 \text { E-02 } \\
(0,22)\end{array}$ & 0 & 0,01 & $\mathrm{G} 1>\mathrm{G} 2 *$ \\
\hline \multicolumn{8}{|l|}{ Pregressa • } \\
\hline & & $0,65(0,49)$ & 1 & $0,15(0,36)$ & 0 & 0,01 & $\mathrm{G} 1>\mathrm{G} 2 *$ \\
\hline \multicolumn{8}{|l|}{ 3) Outras } \\
\hline \multirow[t]{2}{*}{ Adversidades } & Atual• & $1,60(1,27)$ & 1 & $1,10(1,02)$ & 1 & 0,20 & NS \\
\hline & & $4,30(1,70)$ & 4,5 & $2,60(1,31)$ & 2,5 & 0,01 & $\mathrm{G} 1>\mathrm{G} 2 *$ \\
\hline \multicolumn{8}{|c|}{ Pregressa・ } \\
\hline \multicolumn{8}{|c|}{ C) Instab. Financeira } \\
\hline \multirow[t]{2}{*}{ Escore Total } & Atual• & $1,25(1,01)$ & 1 & $0,65(0,81)$ & 0,5 & 0,05 & $\mathrm{G} 1>\mathrm{G} 2 *$ \\
\hline & Pregressa & $2,20(0,76)$ & 2 & $1,75(0,91)$ & 2 & 0,11 & NS \\
\hline
\end{tabular}

Teste t de student $\quad$ NS $=$ não significativo $\quad * p=0,05$

- Teste Não-Paramétrico U de Mann-Whitney

$\mathrm{G} 1=$ risco psicossocial - violência doméstica

$\mathrm{G} 2=$ sem história de risco psicossocial relatada

Observou-se diferença estatisticamente significativa entre os grupos em relação às áreas "adversidade parental", que incluíam tanto eventos atuais quanto pregressos e instabilidade financeira, apenas quanto aos eventos atuais. As famílias do G1, segundo os pais, experimentaram mais eventos estressores quando comparadas às do G2.

Não se observaram diferenças estatisticamente significativas quanto ao escore total e à área "adversidades incidindo diretamente sobre a criança" e respectivas categorias.

Os grupos também foram comparados quanto a cada um dos itens da escala de eventos adversos. Analisaram-se separadamente os eventos atuais e pregressos. Quanto aos eventos atuais, os grupos se diferenciaram significativamente em quatro itens, a saber: "o relacionamento com os colegas piorou", da área "adversidade incidindo diretamente sobre a criança", e "a mãe começou a trabalhar", "consumo de álcool ou droga pelo pai ou pela mãe", e "litígio entre os pais por causa de pensão", da área "adversidade parental". Nas duas áreas, o G1 apresentou maior proporção de indicadores de eventos adversos atuais em comparação com o G2.

Com relação aos eventos pregressos, os grupos se diferenciaram significativamente em oito itens, sete referentes à área "adversidade parental" e um, à área "instabilidade financeira". Na 
área "adversidade parental", os itens com diferença significativa foram: "aumento da ausência da mãe por oito horas ou mais por semana", "aumento de conflitos e brigas entre os pais", "separação dos pais, mãe ou pai se casou de novo", "um dos pais abandonou a família", "consumo de álcool ou droga pelo pai ou pela mãe", e "problema de saúde mental do pai/da mãe", e, na área "instabilidade financeira", o item "perda de emprego do pai/da mãe". Nas duas áreas, o G1 apresentou maior proporção de indicadores de eventos adversos pregressos em comparação com o G2.

Os grupos foram comparados quanto a cada um dos itens da escala de adversidade crônica relatados após três anos do atendimento de G1 pelo Conselho Tutelar, e se diferenciaram significativamente em quatro itens, ou seja, "temperamento difícil do pai", "temperamento difícil da mãe", "conflitos conjugais recorrentes ou crônicos" e "alcoolismo severo do pai ou substituto", com 22,2\% do total dos itens. O G1 apresentou maior proporção de participantes com referência a situações de adversidade crônica em comparação com o G2.

\section{Discussão}

Famílias em risco psicossocial e as medidas do Conselho Tutelar

Ao se analisarem os tipos de violência vivenciados pelas crianças participantes deste estudo, observou-se a ocorrência paralela de diferentes formas de violência, como os subtipos de violência doméstica direcionada à criança e a violência contra a mulher. Esses resultados coincidem com outros estudos em que as diferentes formas de violência doméstica co-ocorrem, evidenciando, ainda, que crianças de lares violentos estão sob risco elevado de sofrerem violência de ambos os pais (Toth et al., 2002).
No presente estudo, o perfil de violência direcionada à criança mostrou semelhança ao relatado no estudo de Tomio (2000), realizado junto ao Conselho Tutelar do Município de Itajaí - Santa Catarina, em que apareceu em primeiro lugar a negligência, seguida pela violência física e psicológica. Entretanto, é importante considerar que esse dado pode não refletir a real distribuição de formas de violência existentes na população, pois nem sempre elas são notificadas, muitas vezes, devido ao desconhecimento sobre o assunto que, em função de fatores socioculturais, tende a ser subestimado, e também por ser difícil tocar em um tema considerado privativo da esfera familiar, que é a autonomia dos pais em relação à educação dos filhos (Guerra, 1998). As dificuldades relacionadas à denúncia da violência doméstica ficam mais acentuadas quando se trata de negligência e de violência psicológica, condições essas mais difíceis de serem confirmadas (Moura $\&$ Reichenheim, 2005).

Os pais (pai e/ou mãe) foram identificados, com maior freqüência, como violadores. Outros estudos confirmam essa tendência, como os resultados de levantamento realizado pela Secretaria Especial de Direitos Humanos, referente ao período de 1999 a 2004, em que as mães $(26,2 \%)$ e os pais $(23,9 \%)$ foram os principais notificados aos Conselhos Tutelares de doze Estados do Brasil (Mena, 2005).

Verificou-se, também, a referência a outros riscos psicossociais simultâneos à violência doméstica, como a discórdia parental recorrente e o abuso de álcool ou drogas pelos pais e dificuldades socioeconômicas, que podem interferir no bem-estar da criança e da família (Cummings et al., 1999; Grych et al., 2000, Jouriles et al., 1998). A discórdia parental recorrente, caracterizada pela intensidade e amplitude do conflito, foi, no momento da denúncia, a condição adversa associada mais freqüente. Esse tipo de discórdia, quando freqüente na 
vida diária, constitui um agente estressor e pode contribuir para problemas emocionais e comportamentais como a ansiedade, a depressão e os transtornos de conduta na criança (Davies \& Cummings, 1998).

A presença de outras condições de vulnerabilidade foi também relatada nos casos incluídos no estudo de Tomio (2000), como o uso abusivo de álcool e drogas, dificuldades socioeconômicas, ausência do pai em seu papel provedor e famílias monoparentais, geralmente, chefiadas por mulheres sem outros suportes econômicos e sociais. Segundo Guerra (1998), há uma tendência a denunciar situações de vulnerabilidade socioeconômica aos órgãos de proteção à criança. Essa tendência foi também observada no estudo de Riva (2006), que examinou a prática de negligência em famílias de baixa renda e concluiu que a negligência não pode ser compreendida apenas no contexto restrito das famílias, pois estas sofrem o impacto de fatores distais, sociais, políticos e econômicos, tendo alertado para a necessidade de se considerar a carência dos serviços oferecidos pelo Estado a essas famílias.

Outro aspecto relevante diz respeito às medidas aplicadas. A atuação do Conselho Tutelar nos casos incluídos neste estudo consistiu em medidas de orientação legal baseadas no Estatuto da Criança e do Adolescente, visando a prevenir a reincidência da violência no ambiente familiar. As orientações em geral foram direcionadas aos pais e trataram dos direitos da criança, buscando esclarecer-lhes as conseqüências da violência doméstica para o desenvolvimento infantil e sugerir outras práticas educativas consideradas adequadas. Destaca-se como relevante tal orientação, já que a punição física, muitas vezes, é vista pelos pais como uma medida necessária e exclusiva para corrigir e educar a criança.

Foram aplicadas, ainda, medidas específicas quanto às dificuldades emergentes identificadas como necessárias para o núcleo familiar e para a criança. Tais medidas priorizaram encaminhamentos voltados para as áreas de proteção social, de saúde mental ou jurídica. Com relação às medidas de saúde mental direcionadas à criança e aos pais, destaca-se a percepção, por parte dos conselheiros, da presença de indicadores de transtorno psíquico associados à denúncia de violência doméstica. As medidas aplicadas não se centraram apenas nas demandas relacionadas diretamente à denúncia de violência, mas incluíram também encaminhamentos para programa de apoio socioeducacional no período de contraturno escolar e para assistência jurídica, nos casos de não recebimento de pensão alimentícia, o que sugere que os conselheiros identificaram também outras violações aos direitos da criança. Esse dado mostra a importância de os conselheiros serem preparados para se sensibilizar com as necessidades do núcleo familiar de modo a lidar com elas de forma mais abrangente, sem se restringirem ao evento alvo da denúncia. Destaca-se que o Conselho Tutelar junto ao qual foi desenvolvido o presente estudo contava com profissionais preparados para a função (psicólogo, assistente social, pedagogo e advogado). Por outro lado, tal necessidade evidencia o fato de o Conselho Tutelar ser um espaço de escuta e de conscientização de direitos do cidadão, o que coloca em destaque a necessidade de formação dos conselheiros (Parré, 2005; Souza et al., 2003), o que nem sempre ocorre, já que grande parte dos Conselhos Tutelares não conta com profissionais especializados para dar suporte ao atendimento e ao encaminhamento dos casos que chegam até eles.

Nesse sentido, o trabalho desenvolvido pelo Conselho Tutelar constitui um dos elementos da rede de apoio social que visa a operar como fator de proteção ao desenvolvimento infantil. Entretanto, a prática descrita como modo de intervenção frente à violência doméstica pelo 
Conselho Tutelar tem um caráter pontual, como resposta a um evento que requer medidas imediatas, não se observando, em geral, um acompanhamento em médio prazo que verifique se o atendimento dos encaminhamentos foi, de fato, realizado, quais os resultados obtidos e como as famílias se encontram tempos depois. Por limites diversos, em geral, as medidas do Conselho Tutelar visam a uma ação imediata que não se complementa por um acompanhamento que verifique se tais medidas são suficientes para ressarcir os direitos da criança e oferecer suporte às famílias.

As famílias incluídas no estudo permaneceram com a guarda dos filhos após o atendimento pelo Conselho Tutelar, o que sugere um contexto de não cristalização da violência. Tal clientela se assemelha àquela que mais comumente é atendida pelo Conselho Tutelar por violações intrafamiliares.

O ambiente familiar pós ações do Conselho Tutelar - recursos e adversidades

$\mathrm{Na}$ avaliação dos recursos do ambiente familiar, detectou-se que eles são semelhantes para ambos os grupos quanto ao ambiente físico, à organização das rotinas e às oportunidades de interação com os pais.

Foram observadas algumas diferenças importantes entre os grupos em relação a questões específicas. Segundo o relato dos pais, mais crianças vítimas de violência doméstica permanecem na rua no período em que não se encontram na escola, o que caracteriza uma situação de menor supervisão por parte dos adultos. Isso ocorreu no nível socioeconômico mais baixo, e sugere que essas crianças usam a rua como uma extensão da própria casa, possivelmente por morarem em espaços pequenos, como é comum em condições de maior vulnerabilidade socioeconômica.
Uma outra diferença observada nos grupos refere-se ao fato de os pais de crianças vítimas de violência doméstica brincarem menos com elas, fato que sugere menos oportunidade de atividades lúdicas com os pais, sendo essas atividades importante fonte de prazer na relação familiar bem como de estimulação ao desenvolvimento.

As famílias de crianças vítimas de violência doméstica experimentaram mais eventos adversos que as sem história de risco psicossocial relatado, principalmente as adversidades parentais pregressas, que incluíram mais situações de ausência da mãe, de conflitos recorrentes e brigas entre os pais, de separação e novo casamento dos pais, de abandono de um dos pais, de consumo de álcool ou droga ou problema de saúde mental por parte de um dos pais.

As famílias também se apresentaram mais expostas à adversidade crônica, como o temperamento difícil dos pais, os conflitos conjugais recorrentes e o alcoolismo severo. Tais condições configuram um ambiente familiar que mantêm no tempo dificuldades associadas à discórdia e a estressores diversos.

Os resultados sugerem que as crianças vítimas de violência doméstica carecem de fatores do ambiente familiar que deveriam servir como proteção para o desenvolvimento infantil, tais como a coesão familiar, compreendida como a ausência de conflitos recorrentes e relações familiares seguras e afetivas (Masten e Garmezy, 1985).

A presença de mais adversidades parentais para o grupo com história de violência doméstica guarda semelhança com os dados de Youssef, Attia e Kamel (1998), que realizaram um estudo sobre punição física com uma amostra da comunidade analisando as características do ambiente familiar e o perfil dos pais. Os autores observaram que as famílias com maior 
possibilidade de risco para o uso de punição física são aquelas com pais usuários de álcool ou drogas e conflito familiar constante, que experimentam sofrimento por rupturas devido ao divórcio ou falecimento dos pais, e que estão em situação de vulnerabilidade socioeconômica.

A compreensão da violência doméstica, enquanto risco psicossocial, demanda um enfoque multidimensional que contemple desde aspectos individuais até uma análise mais ampla da sociedade, devendo-se tomar cuidado para não limitar a análise a relações pontuais de causa e efeito. Deve-se considerar, além das conseqüências de um estressor, a rede complexa de acontecimentos relacionados ao evento-chave para se compreenderem as diferentes reações diante de uma adversidade (Rutter, 1996).

Constata-se, três anos após as ações do Conselho Tutelar, que as famílias atendidas por denúncia de violência doméstica ainda permaneciam expostas a adversidades de grande impacto para o desenvolvimento infantil, embora tenham recebido os mesmos recursos.

\section{Conclusão}

Com base nos dados apresentados, evidenciase a necessidade de dar continuidade ao suporte e acompanhamento de crianças e famílias que enfrentaram situação de risco psicossocial associado à violência doméstica.

A atuação do Conselho Tutelar, como já visto, consistiu em medidas de orientação legal baseadas no Estatuto da Criança e do Adolescente (Brasil, 1990) e encaminhamentos para as áreas de proteção social, de saúde mental ou jurídica, visando a prevenir a volta da violência no ambiente familiar e a agir enquanto disparador de ações das redes de serviços de apoio.
Todavia, essas ações apresentaram um caráter pontual no momento da ocorrência da denúncia e podem não ter sido suficientes para a manutenção da efetividade de tais benefícios. Assim, como forma de responder às demandas identificadas junto às crianças e famílias atendidas pelo Conselho Tutelar, evidencia-se a necessidade de medidas preventivas e de acompanhamento das crianças e das famílias.

Falar de medidas de saúde mental que incluam a prevenção e a intervenção quando se trata da violência doméstica exige algumas reflexões sobre como interferir nas relações familiares quando o problema da violência não é trazido espontaneamente, mas denunciado. É difícil prever como as orientações, encaminhamentos e intervenções serão recebidos pelas famílias, até mesmo porque muitas relataram que a experiência de ser chamada ao Conselho Tutelar, para tratar de denúncia de violência doméstica, trouxe grande apreensão e desgaste emocional. Nesse sentido, a curto prazo, os resultados podem ser favoráveis em função da atuação imediata do Conselho Tutelar, mas, a médio ou a longo prazo, há a necessidade de que sejam avaliados os resultados das intervenções. O planejamento destas deve levar em consideração os aspectos levantados, baseando-se no direito da criança e da família à autonomia, mas buscando conscientização sobre a responsabilidade de cada um. Caso contrário, não há garantias de que se esteja, de fato, respeitando os direitos da criança, e isso põe em risco os benefícios a que a intervenção se propõe.

Na prática, ao colocar o foco mais nos direitos da criança, priorizando mudanças nas práticas educativas empregadas pela família, o conselheiro tutelar pode não discriminar as necessidades da criança e seus recursos pessoais bem como as dificuldades que as famílias apresentam, deixando de reconhecêlas como um conjunto. 
No presente estudo, as famílias relataram história pregressa de dificuldade, com complicadores como problemas de saúde mental dos pais, dependência de álcool e drogas e discórdia conjugal recorrente, fatos que demandam medidas de saúde mental. Destaca-se que o conselheiro tutelar, em sua atuação, deve estar atento, de modo que, ao focalizar os direitos da criança, não deixe de ter a visão da família como um sistema complexo e que também apresenta necessidades, para não haver o risco de o órgão se tornar simplesmente repressor. Nesse sentido, são necessárias medidas de saúde mental e psicossociais, explicitadas em intervenções que mobilizem a capacidade de resolução de problemas pela família.

Analisando alguns dos cuidados metodológicos adotados, destaca-se o controle na composição dos grupos quanto ao nível socioeconômico, o que possibilitou maior segurança na discussão dos dados, principalmente, no que se refere às condições socioeconômicas e à classe social baixa, muitas vezes identificada na literatura como associada à violência doméstica.

No presente estudo, ao se focalizar a família, foi identificado um conjunto de adversidades que co-ocorriam com a violência doméstica e que deu maior peso às adversidades parentais, o que denuncia, dentre outros problemas, os precários cuidados de saúde mental destinados às famílias. Questiona-se se a violência doméstica constitui um ato pontual ou se faz parte de um contexto de vida permeado por adversidades. Nesse sentido, no estudo de riscos psicológicos, nem sempre é possível isolar um risco particular, e a violência doméstica pode ser decorrente de processos complexos em que interagem múltiplas adversidades.

Com base nas questões levantadas, é necessário o desenvolvimento de outros estudos de caráter longitudinal para compreender a trajetória de desenvolvimento das crianças vítimas de violência doméstica, considerando o tempo decorrido após a violência, no sentido de explorar o tempo que a criança e a família levam para se recuperar, e os processos de superação das adversidades, que incluem aspectos como a interação familiar e as formas de enfrentamento.

Quanto aos encaminhamentos dados pelos serviços, lacunas persistem, o que evidencia a necessidade de pesquisas que focalizem os encaminhamentos feitos pelo Conselho Tutelar e os serviços prestados pelos programas de intervenção para as crianças maltratadas e suas famílias, buscando-se verificar a efetividade dessas ações a médio e a longo prazos tanto para as crianças como para as famílias.

\section{Rute Grossi Milani}

Professora do Centro Universitário de Maringá, psicóloga, Doutora em Saúde Mental pela Faculdade de Medicina de Ribeirão Preto - USP.

E-mail: rute@cesumar.br

\section{Sonia Regina Loureiro}

Psicóloga, Doutora, professora do Departamento de Neurologia, Psiquiatria e Psicologia Médica da Faculdade de Medicina de Ribeirão Preto - USP.

E-mail: srloureiro@fmrp.usp.br

Endereço para correspondência:

Rua Anita Garibaldi, 1419 Cep: 14095-480, Ribeirão Preto-SP 


\section{Referências}

Associação Brasileira de Anunciantes, Associação Nacional das Empresas de Pesquisa de Mercado, \& Associação Brasileira dos Institutos de Pesquisa de Mercado. (1997). Critério de Classificação Socioeconômica Brasil (CCSEB). São Paulo: ABA, ANEP, ABIPEME.

Brasil. (1990). Lei Federal no 8069, de 13 de julho de 1990. Estatuto da Criança e do Adolescente. Diário Oficial, Brasília, DF, p. 13.563.

Castro, D. S. P. (2002). Construção de um saber e responsabilidade social na psicologia: o Conselho Tutelar em foro. Tese de Doutorado em Psicologia, Instituto de Psicologia, Universidade de São Paulo, São Paulo.

Cummings, J. G., Pepler, D. J., \& Moore, T. E. (1999). Behavior problems in children exposed to wife abuse: Gender differences. Journal of Family Violence, New York, 14(2), 133-156.

Davies, P. T., \& Cummings, E. M. (1998). Exploring children's emotional insecurity as a mediator of the link between marital relations and child adjustments. Child Development, Chicago, 69, 124-139.

Deslandes, S. F. (1994). Prevenir a violência: um desafio para profissionais de saúde. Rio de Janeiro: FIOCRUZ/ENSP/ CLAVES.

English, D. J., Marshall, D. B., \& Stewart, A. J. (2003). Effects of family violence on child behavior and health during early childhood. Journal of Family Violence, New York, 18(1), 43-57.

Grych, J. H., Jouriles, E. N., Swank, P. R., Mcdonald, R., \& Norwood, W. D. (2000). Patterns of adjustment among children of battered women. Journal of Consulting and Clinical Psychology, Washington, 68(1), 84-94

Guerra, V. N. A. (1998). Violência de pais contra filhos: a tragédia revisitada. São Paulo: Cortez.

Jouriles, E. N., Mcdonald, R., Norwood, W. D., Ware, H. S., Spiller, L. C., \& Swank, P. R. (1998). Knives, guns, and interparent violence: Relations with child behavior problems. Journal of Family Psychology, Newbury Park, 12(2), 178194.

Lisboa, C. S. M., Koller, S. H., Ribas, F. F., Bitencourt, K., Oliveira, L., Porciúncula, L. P., \& De Marchi, R. B. (2002). Estratégias de coping de crianças vítimas e não vítimas de violência doméstica. Psicologia: Reflexão e Crítica, Porto Alegre, 5(2), 345-362.

Marturano, E. M. (1999). Recursos no ambiente familiar e dificuldades de aprendizagem na escola. Psicologia: Teoria e Pesquisa, Brasília, 15(2), 135-142.

Masten, A. S., \& Garmezy, , N. (1985). Risk, vulnerability and protective factors in developmental psychopathology. In B. B. Lahey \& A. E. Kazdin, Advances in clinical child psychology (Vol. 8, pp. 1-52). Nova York: Plenum Press.

Mena, F. (22 de junho de 2005). Mãe lidera ranking da violência infantil. Folha de São Paulo, Caderno C, p. 5.

Moura, A. T. M. S., \& Reichenheim, M. E. (2005). Estamos realmente detectando violência familiar contra a criança em serviços de saúde? A experiência de um serviço público do Rio de Janeiro-Brasil. Cadernos de Saúde Pública, Rio de Janeiro, 21(4), 1124-1133.

Parré, R. R. (2005). Relação escola-Conselho Tutelar: uma visão de suas ações e políticas. Dissertação de Mestrado em Educação, Universidade Estadual de Londrina, Londrina, PR.

Peres, E. L. (2001). Concepções e práticas dos Conselhos Tutelares acerca da violência doméstica contra crianças e adolescentes: um estudo sobre o caso de Curitiba. Dissertação de Mestrado em Psicologia, Universidade Federal do Paraná, Curitiba, PR.

Reppold, C. T., Pacheco, J., Bardagi, M., \& Hutz, C. S. (2002). Prevenção de problemas de comportamento e o desenvolvimento de competências psicossociais em crianças e adolescentes: uma análise das práticas educativas e dos estilos parentais. In C. S. Hutz (Ed.), Situações de risco e vulnerabilidade na infância e na adolescência: aspectos teóricos e estratégias de intervenção (pp. 7-51). São Paulo: Casa do Psicólogo.

Riva, L. C. (2006). A dinâmica do relacionamento entre pais e filhos de famílias de baixa renda: organização doméstica e negligência. Dissertação de Mestrado em Psicologia, Faculdade de Filosofia, Ciências e Letras de Ribeirão Preto, Universidade de São Paulo, Ribeirão Preto, SP.

Rutter, M. (1996). Stress research: Accomplishments and tasks ahead. In R. J. Haggerty, L. R. Sherrod, N. Garmezy, \& M. Rutter (Eds.), Stress, risk and resilience in children and adolescents: Processes, mechanisms and interventions (pp. 354-385). New York: Cambridge University Press.

Santos. (1999). Prefeitura Municipal. Secretaria de Ação Comunitária e Cidadania. Sem dúvidas: Estatuto da Criança e do Adolescente. Santos.

Shonk, S. M., \& Cicchetti, D. (2001). Maltreatment, competency deficits and risk for academic and behavioral maladjustment. Development \& Psychopathology, New York, 37(1), 3-17.

Souza, M. P. R., Teixeira, D. C. S., \& Silva, M. C. Y. G. (2003). Conselho Tutelar: um novo instrumento social contra o fracasso escolar? Psicologia em Estudo, Maringá, 8(2), 71-82.

Tomio, A. G. S. (2000). A violência doméstica contra crianças e adolescentes atendidos no Conselho Tutelar do Município de Itajaí-SC. Dissertação de Mestrado em Saúde Pública, Faculdade de Saúde Pública, Universidade de São Paulo, São Paulo.

Toth, S. L., Cicchetti, D., \& Kim, J. (2002). Relations among children's perceptions of maternal behavior, attributional styles and behavioral symptomatology in maltreated children. Journal of Abnormal Child Psychology, New York, 30(5), 487-501.

Youssef, R. M., Attia, M. S., \& Kamel, M. I. (1998). Children experiencing violence I: Parental use of corporal punishment. Child Abuse \& Neglect, Oxford, 22(10), 959-973.

Yunes, M. A. M., \& Symanski, H. (2001). Resiliência: noção, conceitos afins e considerações críticas. In J. Tavares (Ed.) Resiliência e educação (pp. 13-42). São Paulo: Cortez. 